\title{
Effect of original layer thicknesses on the interface bonding and mechanical properties of Ti-Al laminate composites
}

\author{
Minyu Fan ${ }^{\mathrm{a}}$, Joseph Domblesky ${ }^{\mathrm{b}}$, Kai Jin ${ }^{\mathrm{c}}$, Liang Qin ${ }^{\mathrm{a}}$, Shengqiang Cui ${ }^{\mathrm{a}}$, Xunzhong \\ $\mathrm{Guo}^{\mathrm{a}}$, Naksoo Kim${ }^{\mathrm{c}}, \mathrm{Jie} \mathrm{Tao}^{\mathrm{a}}{ }^{*}$
}

${ }^{a}$ College of Material Science and Technology, Nanjing University of Aeronautics and Astronautics, Nanjing 211106, PR China

${ }^{\mathrm{b}}$ Department of Mechanical Engineering, Marquette University, Milwaukee 53005, USA

${ }^{\mathrm{c}}$ Department of Mechanical Engineering, Sogang University, Seoul 121742, Korea

* Corresponding author. Tel.: +86-25-5211-2911

E-mail addresses: taojie@nuaa.edu.cn (Jie Tao)

Abstract: It's of great significance in high-temperature aeroengine applications for large-surface-area $\mathrm{Ti}-\mathrm{Al}$ laminate composites to be fabricated into $\mathrm{Ti}-\mathrm{Al}_{3} \mathrm{Ti}$ parts by plastic forming and subsequent vacuum hot pressing. Then the original layer thicknesses have an important influence on the interface bonding and mechanical properties of Ti-Al laminate composites, but only few reports about it have been published so far. In the present study, vacuum hot pressing was employed to fabricate Ti-Al laminate composites using Ti and Al foils of different thickness. The resulting interface bond and mechanical properties of Ti-Al laminate composites were then studied to determine the optimum sheet configuration and thickness. To further assess their formability and develop a forming limit diagram (FLD), 0.1/0.15 Ti-Al laminate composites were operated on 
bending and forming tests to provide guidance for subsequent plastic forming of complex geometries. The results indicated that hot pressed laminates composed of alternating 0.1 (Al) and 0.15 (Ti) mm thick sheets exhibited enhanced superior interface bonding and mechanical properties compared with $0.2 / 0.25$ and $0.4 / 0.4$ sheets. The 0.1/0.15 Ti-Al laminate composites had excellent bending characteristics and reasonable formability. Fabrication of a drawn cup further confirms the potential for hot pressed Ti-Al laminate composites to be fabricated into complex shapes.

Key words: vacuum hot pressing; large-surface-area Ti-Al laminate composites; bonding interface; mechanical properties; bending deformation; forming limit

\section{Introduction}

$\mathrm{Ti}_{-} \mathrm{Al}_{3} \mathrm{Ti}$ laminated composites are considered as a candidate material for high-temperature structural parts utilized in aero-engine due to their light weight and excellent mechanical properties [1]. However, the composites cannot be directly fabricated into complex shapes lacking sufficient ductility due to the brittleness of the $\mathrm{Al}_{3} \mathrm{Ti}$ intermetallic, which prevents their further application. Fortunately, in comparison, Ti-Al laminate composites exhibit sufficient ductility and the capability to be fabricated into complicated shapes. Upon completion of forming, a $\mathrm{Ti}-\mathrm{Al}_{3} \mathrm{Ti}$ structure can be achieved by further processing with such techniques as heat treatment and vacuum hot pressing. However, while forming of monolithic sheet materials is generally well characterized, fabrication of multiple layered bi-metal sheets has not been well understood. In comparison to monolithic sheet materials, the formability of laminate 
sheet material is influenced not only by the properties of the individual constituent layers but also by the process used to produce the Ti-Al blank and subsequent bond integrity. Consequently, further research is needed.

At present, several methods are under consideration as a means to produce Ti-Al laminate composites [2]. Most of these methods are based on solid-state joining as many of the material pairs in multiply laminates are metallurgically incompatible and solid-state welding does not involve melting. Therefore, this allows metallurgical bonding to form and suppress intermetallic formation until a desired time is reached. Some of the common solid-state boundary processes are briefly introduced below: (1) Hot roll bonding: High temperature isothermal rolling was used in the two-phase region $(\alpha+\gamma)$. It is applied to billets prepared by ingot or powder metallurgy techniques where the strain rate is closely controlled to prevent the oxidation of the TiAl based alloy sheets $[3,4]$. However, hot roll bonding is considered to be complex and costly $[5,6]$ because it is performed isothermally followed by pack rolling to reduce the deformation resistance and improving stress states. (2) Explosive welding: Detonation wave and kinetic energy of the explosion product result in plastic deformation, local metal melting and even atomic mutual diffusion subsequently at the interface between the titanium and aluminum layers [7]. Thus the metallurgical bonding interface can be obtained [8]. More importantly, this method can be adopted to manufacture large laminates [9]. However, a number of defects, including large area fractures, violent bending deformation and serious surface burns, would easily occur in the ultrathin multilayer 
laminates prepared by explosive bonding $[10,11]$. (3) Other techniques such as physical vaporous deposition [12], mechanical alloying [13, 14] and rapid solidification processing [15] have also been used to fabricate Ti-Al laminate composites recently. However, those methods are just limited to the production of small scale parts.

Compared with the methods above, vacuum hot pressing represents a promising alternative method for fabricating Ti-Al laminate composites [16], showing the capability to achieve high integrity bonding with minimal oxidation on the basis of high temperature element diffusion mechanism and super-plastic principle $[17,18]$. Nevertheless, until recently this method has only been suitable to fabricate small-scale laminates owing to the limit of existing vacuum hot pressing furnaces [19]. However, a vacuum hot pressing furnace, which has the capability to fabricate laminate composites with a maximum area of $300 \mathrm{~mm} \times 300 \mathrm{~mm}$, has recently been designed and installed at NUAA.

Ti-Al laminate composites are of fundamental importance in the aerospace industry, but only few reports about the influence of the original layer thickness (titanium and aluminum) have been published so far [20]. In the current study, vacuum hot pressing was employed to fabricate large-surface-area Ti-Al laminate composites using titanium and aluminum foils of different thicknesses. A particular attention was paid to the effect of the original layer thickness on the interface bonding and mechanical properties in Ti-Al laminate composites. Then, the formability of Ti-Al laminate composites was evaluated by means of bending deformation and forming tests. 


\section{Experimental methods and materials}

Pure Ti and AA1060 Al foils were used and the chemical composition of each material is given in Tables 1 and 2. A $1.2 \mathrm{~mm}$ blank thickness was selected as this blank thickness represents a common thickness used to fabricate a flame tube of the annular combustor in gas turbine engines. Three different foil thicknesses were used and summarized in Table 3. The laminate composites prepared from Al foils of 0.4, 0.2 and $0.1 \mathrm{~mm}$ thick and Ti foils of $0.4,0.25$ and $0.15 \mathrm{~mm}$ thick were denoted later as $0.4 / 0.4$ Ti-Al laminate composites, 0.2/0.25 Ti-Al laminate composites and 0.1/0.15 Ti-Al laminate composites respectively.

$\mathrm{Ti}$ and Al foils were cut into $300 \mathrm{~mm}$ x $300 \mathrm{~mm}$ squares using a wire electrical discharge machine (WEDM) to prepare each blank. To remove any contamination on the surfaces, each foil was cleaned prior to hot pressing each laminate. For the Ti foils, each piece was cleaned in a bath consisting of 35 pct nitric acid $\left(\mathrm{HNO}_{3}\right), 5$ pct fluoric acid (HF), and water. The aluminum foils were also cleaned according to the following procedures. Each piece was first cleaned in an alkaline solution of $30 \mathrm{~g} / \mathrm{l}$ sodium hydroxide $(\mathrm{NaOH})$ at $50-60^{\circ} \mathrm{C}$. The aluminum foils were subsequently immersed in 300-350g/1 nitric acid $\left(\mathrm{HNO}_{3}\right)$ aqueous solution at room temperature. The final step consisted of rinsing the $\mathrm{Al}$ foils in water and then in ethanol. After drying the surface of each foil using a hot air blow dryer, the $\mathrm{Al}$ and $\mathrm{Ti}$ foils were stacked in an alternating sequence to form a laminated structure.

Vacuum hot pressing was performed as follows. After mounting a laminate stack in 
the chamber, a pressure of $5 \mathrm{MPa}$ was applied at room temperature to ensure good contact between the metals using a hydraulic ram. Each sample was then heated in a vacuum of $0.01 \mathrm{~Pa}$ at $550^{\circ} \mathrm{C}$ for $3 \mathrm{~h}$. During this time, the $5 \mathrm{MPa}$ pressure was continuously applied to allow diffusion bonding between the Ti and Al foils. Following vacuum hot pressing, the samples were furnace-cooled to room temperature.

The interface bonding, microhardness and tensile properties of each fabricated Ti-Al laminate composites were investigated to characterize the resulting interface morphology and identify an optimum sample configuration to be used in formability testing. After fabrication, the specimens were cut, mounted in a cold setting resin, mechanically polished initially with a grade 800 abrasive paper and finally using a polishing machine with a $1 \mu \mathrm{m}$ diamond suspension. Microstructural observations and element diffusion analysis using a HITACHI TM 3000 scanning electron microscope (SEM) were employed to study the interface bonding property. Microhardness measurements were taken using a Shanghai BM HXS-1000A microhardness tester with an applied force of 100, $15 \mathrm{~s}$ loading time and appropriate interval between the measuring points for different Ti-Al laminate composites. Tensile samples with gauge dimensions of $50 \mathrm{~mm} \times 12.5 \mathrm{~mm} \times 1.15 \mathrm{~mm}$ (composites thickness), made from fabricated composites, were subjected to tension tests on a SANS CMT5105 electronic universal testing machine with a constant crosshead travel speed of $2 \mathrm{~mm} \cdot \mathrm{min}^{-1}$ according to ASTM E8-08 specifications. The reported data for all the mechanical tests were average values of three tested specimens. In order to investigate the plastic forming ability of 
Ti-Al laminate composites with the best original layer thicknesses, the three point bending test was operated on un-notched specimens with dimensions of $50 \mathrm{~mm} \times 10$ $\mathrm{mm} \times 1.15 \mathrm{~mm}$ (composites thickness) where the loading span was $24 \mathrm{~mm}$, using a fixture that was mounted in the SANS CMT5105 electronic universal testing machine. The tests were carried out under displacement control at a rate of $1 \mathrm{~mm} / \mathrm{min}$. The bending radius was $5 \mathrm{~mm}$ and the bending angle was calculated by measuring the displacement of the bending head. The bending tests were conducted until a bend angle of 180 degrees was achieved. The tests was interrupted at $10^{\circ}\left(\mathrm{e} . \mathrm{g} \sim 100^{\circ}, \sim 110^{\circ}, \sim 120^{\circ}\right.$, $\sim 130^{\circ}, \sim 140^{\circ}, \sim 150^{\circ}, \sim 160^{\circ}, \sim 170^{\circ}$ and $\sim 180^{\circ}$ respectively). The specimens after different bend angles could be observed under a HITACHI TM 3000 scanning electron microscope to check for the presence of voids and characterize the damage evolution. As tensile testing provides limited information of actual forming performance, the sheet formability test machine and ARGUS grid strain measurement system were used to analyze grid strain and construct a forming limit diagram (FLD) according to the Nakazima test method for the formability of Ti-Al laminate composites with the best original layer thicknesses. Subsequently, the 90-mm-diamater Ti-Al laminate circle was drawn into a cylindrical cup to evaluate the actual forming ability using a hydraulic forming press and 50-mm-diameter punch.

\section{Results and discussion}

\subsection{Effect of original layer thicknesses on the interface bonding and mechanical properties of Ti-Al laminate composites}


The resulting interface morphology of each Ti-Al sample configuration is shown in Figure 1. It can be seen that complete bonding is achieved between the titanium and aluminum layers in all three samples, as evidenced by the visible inexistence of cracks and microvoids. This also confirms that the pressure of $5 \mathrm{MPa}$ is valid. However, as shown in Figure 1(b), (e) and (h), the interface morphology transitions from a straight to a wavy appearance on the local level as the foil thickness is decreased from 0.4 to 0.1 $\mathrm{mm}$. A likely reason for this phenomenon is that the aspect ratio of each layer (thickness/width) is on the order of $10^{-4} \mathrm{~mm}$. As sticking friction applies at the interface and full contact can be assumed, this is analogous to conditions existing in plane strain compression of thin pieces. As a result, deformation is highly inhomgeneous and concentrated along planes diagonal to the interface with the result that triangular shaped dead metal zones extend into the one of the foils. One consequence of this is that the total surface area of the wavy interface morphologies is larger than that of the specimen with a linear morphology.

The chemical composition and confirmation of metallurgical bonding at the interface were also investigated using EDS. In all three samples, it can be seen that the percentage of titanium and aluminum decrease abruptly at the interface, which demonstrates the formation of a metallurgical bond between two foils. The EDS survey also shows that the thickness of the diffusion layers at the interface has an inverse relationship with the foil thickness used, as evidenced by the observation that the thicknesses of the diffusion layers for the $0.4 / 0.4,0.2 / 0.25$ and $0.1 / 0.15$ Ti-Al laminates 
are 4.1, 4.4 and 5.2 microns respectively. This inverse relationship is because the inter diffusion of $\mathrm{Al}$ and $\mathrm{Ti}$ is promoted by mechanically induced atomic displacement and grain boundary diffusion. Based on the similarities of the vacuum hot pressing conditions and starting materials, the increased diffusion layer at the interface can be attributed to the increased interface pressure at the lowest foil thicknesses which results in more local softening aluminum and faster diffusion. Hence, 0.1/0.15 Ti-Al laminate composites have a better interface bonding property owing to larger interface waves and thicker element diffusion layers.

To further assess the interface properties of each Ti-Al laminate configuration, microhardness testing was also performed after vacuum hot pressing. The results of the microhardness surveys of each specimen are shown in Figure 2. The microhardness values of the individual aluminum and titanium layers in all three configurations are 29.1HV and $116.0 \mathrm{HV}$ respectively. These values are somewhat lower than those of the original $\mathrm{Al}$ and Ti foils which have microhardness of $40.1 \mathrm{HV}$ and $170.2 \mathrm{HV}$ respectively. Their decrease in hardness is due to annealing of the $\mathrm{Ti}$ and $\mathrm{Al}$ foils which occurred during vacuum hot pressing. In comparison, the microhardness values of the bonding interfaces are found to be intermediate between those of the titanium and aluminum layers. Furthermore, the interface hardness for the specimens shows a small increase as the individual foil thickness is reduced. Based on the hardness values shown in Figure 2, the minimum hardness of $40 \mathrm{HV}$ was obtained in 0.4/0.4 Ti-Al laminate composites. It is due to the formations of metallurgical bonds and element diffusion layers between 
titanium and aluminum layers during the vacuum hot pressing process. Besides, the expansion of the total surface areas and thickening of element diffusion layers are also fundamental reasons.

The tensile properties of the Ti-Al laminate composites are summarized in Table 4. Yield-strength ratio decreases and plasticity increases gradually as the individual foil thickness is reduced. As shown in Figure 3, the 0.1/0.15 Ti-Al laminate composites also have a long uniform tensile deformation zone, indicating a better plastic forming property. When the original layer thicknesses decline, the interface number rises and then the coordinated deformation capacity of $\mathrm{Ti}-\mathrm{Al}$ laminate composites is obviously improved owing to more interfaces. Interfaces play an important role in traction coordination between the aluminum layers and titanium layers, and hence increase plasticity and decrease yield-strength ratio of Ti-Al laminate composites. Specially, the interface wavelength grows gradually from 0.4/0.4 Ti-Al laminate composites to 0.1/0.15 Ti-Al laminate composites, and then total surface areas of interfaces expand. Meanwhile, element diffusion layers thicken gradually from 0.4/0.4 Ti-Al laminate composites to $0.1 / 0.15$ Ti-Al laminate composites. Therefore, the bonding properties of Ti-Al laminate composites are improved evidently. The simple tension tests confirm the discussion regarding the microhandness test.

Based on the data shown in Table 4, it is evident that the yield strength and tensile strength of 0.4/0.4 Ti-Al laminate composites are obviously higher than those of the other two Ti-Al laminate composites. This is because macro-delamination forms and the 
aluminum layers are completely broken at the early tensile stage. Hence, only titanium layers deform during post tensile process of 0.4/0.4 Ti-Al laminate composites, improving the yield strength and tensile strength. Furthermore, the elongations of three Ti-Al laminate composites are larger (more than 30\%), indicating a better plasticity. However, delaminations occur at 0.4/0.4 and 0.2/0.25 Ti-Al laminate composites after tensile process, as shown in Figure 4. Therefore, 0.1/0.15 Ti-Al laminate composites have a better plasticity forming ability than $0.4 / 0.4$ and $0.2 / 0.25$ Ti-Al laminate composites.

In comparison, the Ti-Al explosive cladding composites have larger tensile strength (about $424.7 \mathrm{MPa}$ ) than Ti-Al laminate composites prepared by vacuum hot pressing due to the strong work hardening during explosive bonding process [9]. However, the lower elongation of Ti-Al explosive cladding composites (about 19.9\%) represents an insufficient ductility, which prevents their wider application. Moreover, in the tensile tests, the Al layers have shown a fracture in a lower load firstly resulting from the worse interface deformation coordination compatibility of Ti-Al explosive cladding composites. Thus Ti-Al laminate composites prepared by vacuum hot pressing have a better comprehensive plastic forming ability than Ti-Al explosive cladding composites.

\subsection{Bending deformation of 0.1/0.15 Ti-Al laminate composites}

The morphology of the $0.1 / 0.15$ Ti-Al laminate composites is shown in Figure 5 after $100^{\circ}$ and $110^{\circ}$ bending. The results show that overall basic layered structure of the 
0.1/0.15 Ti-Al laminate composites is maintained and that no cracks or voids are evident. The good ability is thought to originate from the soft texture and cushion of the aluminum layers during the bending process, which can reduce the stress concentration and thus inhibit the formation and growth of the micro cracks. This excellent bending property is an obvious advantage of the $0.1 / 0.15 \mathrm{Ti}-\mathrm{Al}$ laminate composites prepared by vacuum hot pressing. A good bending performance means suitability to plastic forming.

With an increase in the bending angle to $120^{\circ}$, it is seen that no cracks occur in the aluminum or titanium layers, but some micro cracks have formed at the bonding interfaces, as shown in Figure 6. The microstructural investigations also indicate that the bonding interfaces are weaker than the matrix aluminum and titanium layers, resulting from the local defect areas composed of confused ingredients and loose texture at the bonding interface. During vacuum hot pressing process, the aluminum layers are softened locally and then the local defect areas are formed after cooling. Consequently, the local defect areas are on stress concentration and easy to initiate micro cracks during bending deformation. Furthermore, the crystal structures mismatch between the aluminum and titanium layers, making it almost impossible for the slip-bands to slide through the bonding interfaces. Therefore, the formation of cracks at the bonding interfaces is a characteristic feature of the deformation. The initiation ways of micro cracks are the nucleation, growth and aggregation of micro holes. Moreover, the nucleation modes of micro holes are the breakage and separation of the second phases (or inclusions) from the matrix interface. Hence, the $0.1 / 0.15 \mathrm{Ti}-\mathrm{Al}$ laminate composites 
cannot be bended up to $120^{\circ}[21]$.

With continued bending to $130^{\circ}, 140^{\circ}, 150^{\circ}$ and $160^{\circ}$, the morphology of the 0.1/0.15 Ti-Al laminate composites is shown in Figure 7. Unlike the previous phenomena, two micro cracks extend in two directions, as shown in Figure 7(a). In the first direction, which is consistent with the loading direction, the micro cracks develop at defect areas and then propagate across them. The perpendicular cleavage cracks are blunted by the aluminum layers when the cracks reach the aluminum/defect areas interfaces, however, the micro cracks still broaden. In the other direction paralleling to interface, two micro cracks extend to each other until the mutual connection, and then the local delamination occur at the bonding interface (Figure 7(b)). Moreover, when the 0.1/0.15 Ti-Al laminate composites are bent to $150^{\circ}$ (Figure $7(\mathrm{c})$ ), the two adjacent local delaminations begin to connect with each other. This is because local delaminations broaden and extend to both sides along the bonding interface direction with the increasing bending angle. Besides, with the further increase of the bending angle, several local delaminations extend to each other until the mutual connection, finally forming the overall delamination at the bonding interface (Figure 7(d)).

Figure 8 shows that some micro cracks form in the aluminum and titanium layers near the local delaminations. It is mainly due to the extended obstruction along the bonding interface direction with the increasing bending angle. The energy absorption ability of the aluminum and titanium layers allows numerous cracks to develop and extend within each bonding interface before failure. With a permanent increase in the 
number of micro cracks at the bonding interfaces, the titanium and aluminum layers gradually undergo total external load. Therefore, the plastic flow that took place in the aluminum and titanium layers was restricted to small regions between opposite micro cracks in the neighbouring defect areas. When the number and distribution of micro cracks in the bonding interfaces reached a critical limit, final failure occurred by shearing fracture of the matrix layers [16]. Besides, a triangular delamination occurs at the local bonding interface and a large tear forms in the titanium layer, as shown in Figure $8(\mathrm{~b})$. Owing to the extended obstruction, local delaminations broaden sharply along the loading direction and micro cracks initiate in the trough of the titanium layer and then extend to the matrix titanium layer sequentially. Furthermore, zigzag micro cracks, with obvious shear bands at the frontier, spread over both sides of the tear. Progressive cracking in the bonding interfaces creates stress concentration points at the metal/defect areas interfaces, resulting in shear bands that propagate from the crack tip to successive matrix layers. Meanwhile, micro cracks continue to extend along the deepened shear bands, eventually leading to the fracture of the specimens.

The damage modes of Ti-Al laminate composites include crack initiation, crack growth, crack connection, and delamination, which are similar with those of metal-intermetallic laminate (MIL) composites such as $\mathrm{Ti}-\mathrm{Al}_{3} \mathrm{Ti}$ laminate composites. It is noted that numerous brittle cracks can be still identified in the inter-metallic matrix layers even many debris avalanched down the $\mathrm{Al}_{3} \mathrm{Ti}$ matrix layers of $\mathrm{Ti}-\mathrm{Al}_{3} \mathrm{Ti}$ laminate composites in the vicinity of the loading point due to high inherent brittleness of 
intermetallic $\mathrm{Al}_{3} \mathrm{Ti}$ [22]. However, cracks initiate and grow without any deflection only at the bonding interface of Ti-Al laminate composites. In addition, unlike the brittle intermetallic matrix $\mathrm{Al}_{3} \mathrm{Ti}$, the ductile reinforcement of $\mathrm{Ti}$ and $\mathrm{Al}$ layers can be subjected to bending deformation without any debris.

\subsection{Forming limit diagram of 0.1/0.15 Ti-Al laminate composites}

As shown in Figure 9, the 0.1/0.15 Ti-Al laminate composites have a high forming limit, demonstrating an excellent plastic forming property. Therefore, the Ti-Al laminate composites are considered to be suitable for plastic forming to fabricate parts with more complicated geometries. Subsequently, the 90-mm-diamater Ti-Al laminate circle was drawn into a cylindrical cup of diameter $54 \mathrm{~mm}$ and height $28 \mathrm{~mm}$ using a hydraulic forming press and 50-mm-diameter punch. As expected, examination of the drawn cup shows no evidence of any cracks or delaminations (Figure 9(c)). Furthermore it has experimentally been shown that the drawability of the pure titanium sheets can be improved by laminating with the aluminum sheets.

\section{Conclusions}

(1) The 0.1/0.15 Ti-Al laminate composites exhibited better interface bonding and mechanical properties than the $0.4 / 0.4$ and $0.2 / 0.25 \mathrm{Ti}-\mathrm{Al}$ laminate composites owing to larger interface waves, thicker element diffusion layers and resulting better coordinated deformation capacity.

(2) After $110^{\circ}$ bending, no marco-delamination and micro cracks formed at the bonding interfaces of $0.1 / 0.15 \mathrm{Ti}$-Al laminate composites, indicating the excellent 
bending deformation property. The damage modes of Ti-Al laminate composites included crack initiation, crack growth, crack connection, and delamination.

(3) The 0.1/0.15 Ti-Al laminate composites had a high forming limit and could be drawn into a cylindrical part of diameter $50 \mathrm{~mm}$ and height $28 \mathrm{~mm}$ without any cracks and delaminations, proving the sufficient ductility.

\section{Acknowledgements}

This work was supported by the National Natural Science Foundation of China (No. 51475231), A Project Funded by the Priority Academic Program Development of Jiangsu Higher Education Institutions, the Funding of Jiangsu Innovation Program for

Graduate Education (No. KYLX_0263), National Science Foundation of Jiangsu Province (No. SBK2015022427), The Fundamental Research Funds for the Central Universities (NO.NJ20150023), Foundation of Graduate Innovation Center in NUAA (kfjj20150606) and the Fundamental Research Funds for the Central Universities.

\section{References}

[1] J. Lapin, TiAl-based alloys: Present status and future perspectives, Conf. P. Metal. 19 (2009) 2009.

[2] K. Kothari, R. Radhakrishnan, N.M. Wereley, Advances in gamma titanium aluminides and their manufacturing techniques, Prog. Aerosp. Sci. 55 (2012) 1-16.

[3] M. Ma, P. Huo P, W.C. Liu, G.J. Wang, D.M. Wang, Microstructure and mechanical properties of $\mathrm{Al} / \mathrm{Ti} / \mathrm{Al}$ laminated composites prepared by roll bonding, Mat. Sci. 
Eng. A. 636 (2015) 301-310.

[4] K.P. Rao, Y. Prasad, K. Suresh, Hot working behavior and processing map of a $\gamma$-TiAl alloy synthesized by powder metallurgy, Mater. Des. 32 (2011) 4874-4881.

[5] X. Liang, B. Liu B, Y. Liu Y, H.Z. Li, Z.Y. Gan, B. Liu, Y.H. He, An investigation on microstructural and mechanical properties of powder metallurgical TiAl alloy during hot pack-rolling, Mat. Sci. Eng. A. 619 (2014) 265-273.

[6] S. Mousa, G.Y. Kim, Experimental study on warm roll bonding of metal/polymer/metal multilayer composites, J. Mater. Process. Technol. 222 (2015) 84-90.

[7] V.I. Lysak, S.V. Kuzmin, Energy balance during explosive welding, J. Mater. Process. Technol. 222 (2015) 356-364.

[8] M.A. Habib, H. Keno, R. Uchida, A. Mori, K. Hokamoto, Cladding of titanium and magnesium alloy plates using energy-controlled underwater three layer explosive welding, J. Mater. Process. Technol. 217 (2015) 310-316.

[9] H. Xia, S. Wang, H. Ben, Microstructure and mechanical properties of Ti/Al explosive cladding, Mater. Des. 56 (2014) 1014-1019.

[10] J. Sun, W.P. Tong, L. Zuo, Z.B. Wang, Low-temperature plasma nitriding of titanium layer on Ti/Al clad sheet, Mater. Des. 47 (2013) 408-415.

[11] I.A. Bataev, A.A. Bataev, V.I. Mali, D.V. Pavliukova, Structural and mechanical properties of metallic-intermetallic laminate composites produced by explosive welding and annealing, Mater. Des. 35 (2012) 225-234.

[12] R. Ali, M. Sebastiani, E. Bemporad, Influence of Ti-TiN multilayer PVD-coatings 
design on Residual stresses and Adhesion, Mater. Des. 75 (2015) 47-56.

[13] B. Guo, S. Ni, R. Shen, M. Song, Fabrication of Ti-Al ${ }_{3} \mathrm{Ti}$ core-shell structured particle reinforced $\mathrm{Al}$ based composite with promising mechanical properties, Mat. Sci. Eng. A. 639 (2015) 269-273.

[14] R. Yang, Z.Y. Zhang, Y.T. Zhao, G. Chen, Y.H. Guo, M.P. Liu, J. Zhang, Effect of multi-pass friction stir processing on microstructure and mechanical properties of Al3Ti/A356 composites, Materials Characterization, Mater. Charact. 106 (2015) $62-69$.

[15] C. Kenel, C. Leinenbach, Influence of cooling rate on microstructure formation during rapid solidification of binary TiAl alloys, J. Alloy. Compd. 637 (2015) 242-247.

[16] M. Konieczny, Mechanical properties of $\mathrm{Ti}-\left(\mathrm{Al}_{3} \mathrm{Ti}+\mathrm{Al}\right)$ and $\mathrm{Ti} / \mathrm{Al}_{3} \mathrm{Ti}$ laminated composites, Compos. Theory. Pract. 13 (2013) 102-106.

[17] Y. Sun, J. Chen, F.M. Ma, K. Ameyama, W.L. Xiao, C.L. Ma, Tensile and flexural properties of multilayered metal/intermetallics composites, Mater. Charact. 102 (2015) 165-172.

[18] M. Krasnowski, S. Gierlotka, T. Kulik, Nanocrystalline matrix $\mathrm{Al}_{3} \mathrm{Ni}_{2}-\mathrm{Al}-\mathrm{Al}_{3} \mathrm{Ni}$ composites produced by reactive hot-pressing of milled powders, Intermetallics. 54 (2014) 193-198.

[19] H. Wu, G.H. Fan, B.C. Jin, L. Geng, X.P. Cui, M. Huang. Fabrication and mechanical properties of $\mathrm{TiB}_{\mathrm{w}} / \mathrm{Ti}-\mathrm{Ti}(\mathrm{Al})$ laminated composites, Mater. Des. 89 (2015) 697-702.

[20] X. Shao, X.L. Guo, Y.F. Han, W.J. Lu, J.N. Qin, D. Zhang, Characterization of the diffusion bonding behavior of pure $\mathrm{Ti}$ and $\mathrm{Ni}$ with different surface roughness 
during hot pressing, Mater. Des. 65 (2015) 1001-1010.

[21] J. Yanagimoto, T. Oya, S. Kawanishi, N. Tiesler, T. Koseki, Enhancement of bending formability of brittle sheet metal in multilayer metallic sheets, Cirp. Ann-Manuf. Techn. 59 (2010) 287-290.

[22] Y. Cao, C.H. Guo, S.F. Zhu, N.X. Wei, R.A. Javed, F.C. Jiang, Fracture behavior of $\mathrm{Ti} / \mathrm{Al}_{3} \mathrm{Ti}$ metal-intermetallic laminate (MIL) composite under dynamic loading, Mat. Sci. Eng. A. 637 (2015) 235-242.

Table 1 Chemical composition of the titanium foils

Table 2 Chemical composition of the AA1060 aluminum foils

Table 3 Summary of Ti-Al laminate samples used in the study

Table 4 Tensile properties of Ti-Al laminate composites

Fig.1 The morphology, interface and element distribution for Ti-Al laminate composites:

(a) (b) (c) 0.4 (Al) and 0.4 (Ti) mm thick; (d) (e) (f) 0.2 (Al) and 0.25 (Ti) mm thick; (g)

(h) (i) $0.1(\mathrm{Al})$ and 0.15 (Ti) $\mathrm{mm}$ thick

Fig.2 The microhardness of Ti-Al laminate composites: (a) $0.4(\mathrm{Al})$ and 0.4 (Ti) mm thick; (b) 0.2 (Al) and 0.25 (Ti) mm thick; (c) 0.1 (Al) and 0.15 (Ti) mm thick

Fig.3 Tensile stress-strain curves of Ti-Al laminate composites

Fig.4 Fracture morphologies of Ti-Al laminate composites

Fig.5 The morphology of the Ti-Al layers at bend angles of (a) $100^{\circ}$ and (b) $110^{\circ}$

Fig. 6 The morphology of the Ti-Al layers after bending deformation of $120^{\circ}$ : (a) $100 \times$; 
(b) $11000 \times$; (c) $12000 \times$

Fig.7 The morphology of the Ti-Al layers after bending deformation: (a) $130^{\circ}$; (b) $140^{\circ}$; (c) $150^{\circ} ;$ (d) $160^{\circ}$

Fig. 8 The morphology of the Ti-Al layers after bending deformation: (a) $170^{\circ}$; (b) $180^{\circ}$ Fig.9 The forming properties of Ti-Al laminate composites: (a) forming limit sheets; (b) forming limit curve; (c) Ti-Al laminated parts 
Table 1 Chemical composition of the titanium foils

\begin{tabular}{cccccccc}
\hline Foils & $\mathrm{Ti}$ & $\mathrm{Fe}$ & $\mathrm{C}$ & $\mathrm{N}$ & $\mathrm{H}$ & $\mathrm{O}$ & Other elements \\
\hline Titanium foils & Margin & $<0.2 \%$ & $<0.08 \%$ & $<0.03 \%$ & $<0.015 \%$ & $<0.18 \%$ & $<0.4 \%$ \\
\hline
\end{tabular}


Table 2 Chemical composition of the AA1060 aluminum foils

\begin{tabular}{cccccccccc}
\hline Foils & $\mathrm{Al}$ & $\mathrm{Si}$ & $\mathrm{Cu}$ & $\mathrm{Mg}$ & $\mathrm{Zn}$ & $\mathrm{Mn}$ & $\mathrm{Ti}$ & $\mathrm{V}$ \\
\hline Aluminum foils & $99.6 \%$ & $<0.25 \%$ & $<0.05 \%$ & $<0.05 \%$ & $<0.05 \%$ & $<0.05 \%$ & $<0.03 \%$ & $<0.05 \%$ \\
\hline
\end{tabular}


Table 3 Summary of Ti-Al laminate samples used in the study

\begin{tabular}{cccccc}
\hline Laminate & Aluminum & Titanium & Al/Ti volume & Al/Ti & Total \\
composites & layer(mm) & layer(mm) & ratio(\%) & structure & thickness(mm) \\
\hline (1) & 0.4 & 0.4 & 50 & $1 / 2$ & 1.20 \\
(2) & 0.2 & 0.25 & 53 & $2 / 3$ & 1.15 \\
(3) & 0.1 & 0.15 & 53 & $4 / 5$ & 1.15 \\
\hline
\end{tabular}


Table 4 Tensile properties of Ti-Al laminate composites

\begin{tabular}{|c|c|c|c|c|c|c|}
\hline \multirow{3}{*}{ Laminates } & \multirow{3}{*}{$\begin{array}{l}\text { Al-Ti layer } \\
\text { thickness ratio }\end{array}$} & \multirow{3}{*}{$\begin{array}{l}\text { Elastic } \\
\text { modulus } \\
(\mathrm{GPa})\end{array}$} & \multirow{3}{*}{$\begin{array}{l}\text { Yield } \\
\text { strength } \\
(\mathrm{MPa})\end{array}$} & \multirow{3}{*}{$\begin{array}{l}\text { Tensile } \\
\text { strength } \\
(\mathrm{MPa})\end{array}$} & \multirow{3}{*}{$\begin{array}{c}\text { Yield-Tensile } \\
\text { strength ratio } \\
\text { (\%) }\end{array}$} & \multirow{3}{*}{$\begin{array}{c}\text { Elongation } \\
\text { at fracture } \\
(\%)\end{array}$} \\
\hline & & & & & & \\
\hline & & & & & & \\
\hline (1) & $0.4 / 0.4$ & $63.91 \pm 1.14$ & $225.05 \pm 4.26$ & $288.03 \pm 4.93$ & $78.19 \pm 2.24$ & $36.56 \pm 1.36$ \\
\hline (2) & $0.2 / 0.25$ & $72.91 \pm 1.27$ & $154.99 \pm 3.87$ & $213.32 \pm 1.66$ & $72.66 \pm 2.37$ & $37.28 \pm 1.02$ \\
\hline (3) & $0.1 / 0.15$ & $88.20 \pm 1.23$ & $140.70 \pm 3.93$ & $223.67 \pm 1.13$ & $62.91 \pm 1.79$ & $34.61 \pm 0.67$ \\
\hline
\end{tabular}



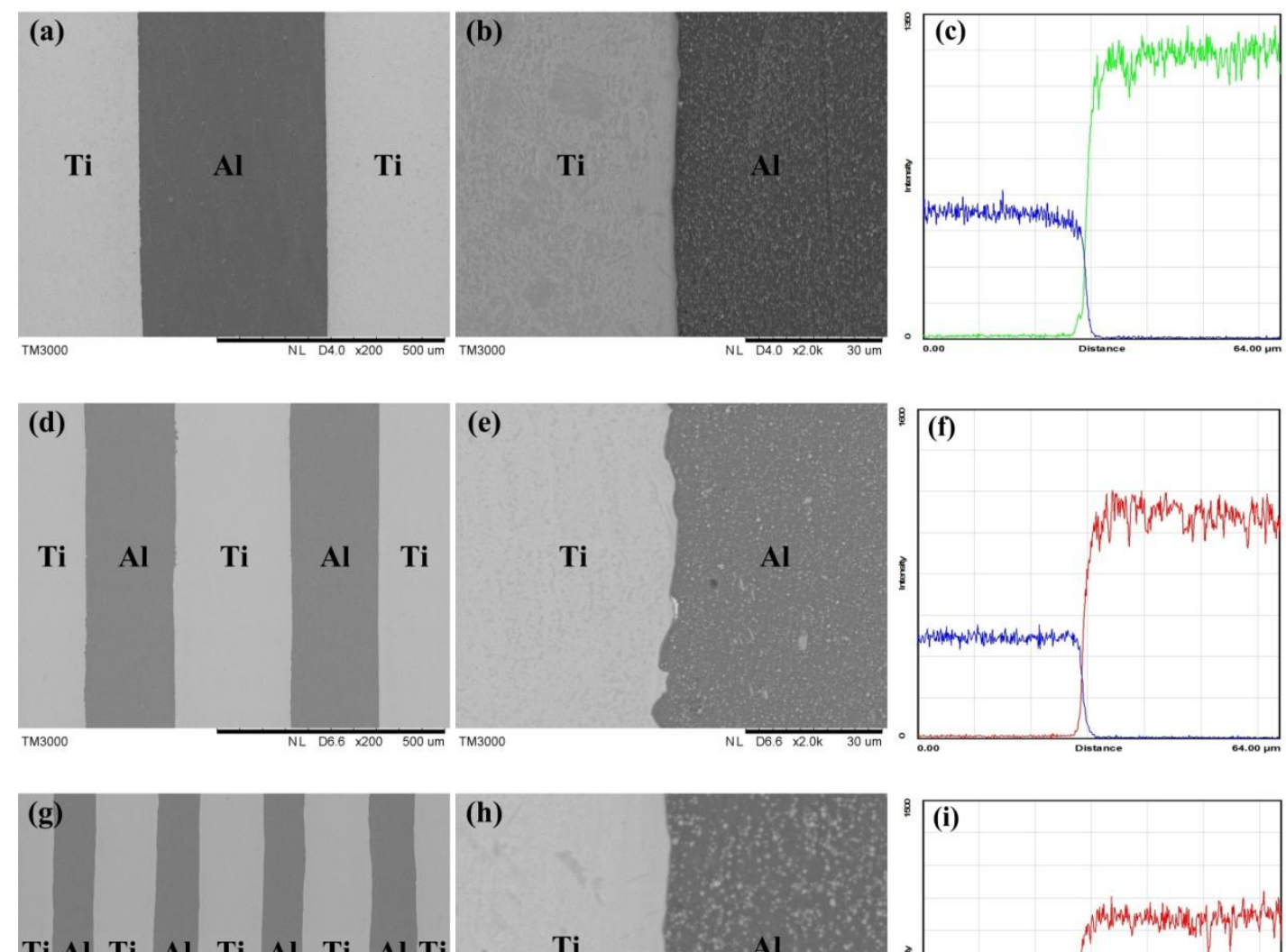

(h)
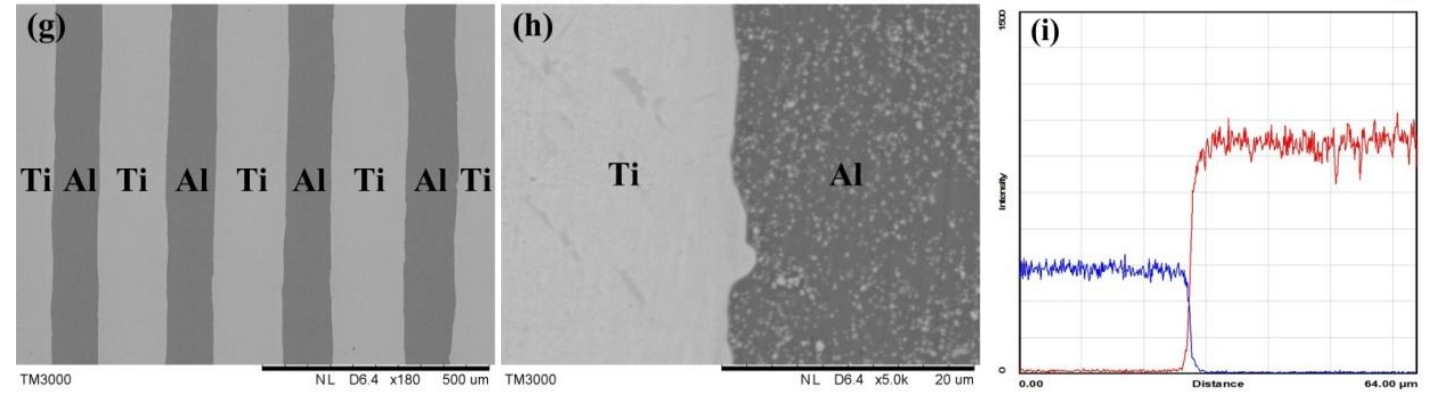

Fig.1 The morphology, interface and element distribution for Ti-Al laminate composites: (a)

(b) (c) 0.4 (Al) and 0.4 (Ti) mm thick; (d) (e) (f) 0.2 (Al) and 0.25 (Ti) mm thick; (g) (h) (i) 0.1

(Al) and 0.15 (Ti) $\mathrm{mm}$ thick 

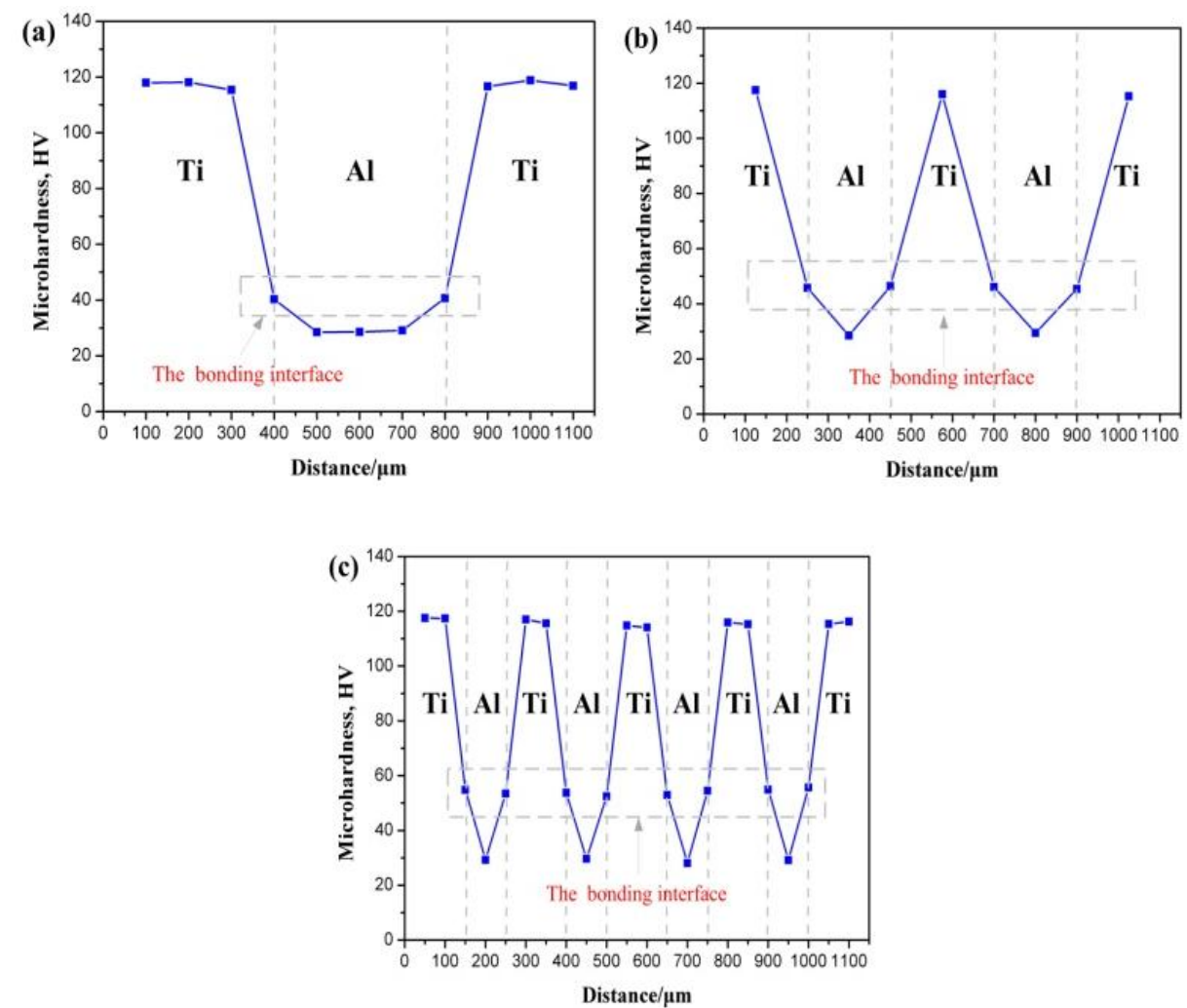

Fig.2 The microhardness of Ti-Al laminate composites: (a) 0.4 (AI) and 0.4 (Ti) mm thick; (b)

$0.2(\mathrm{Al})$ and 0.25 (Ti) mm thick; (c) 0.1 (Al) and 0.15 (Ti) mm thick 


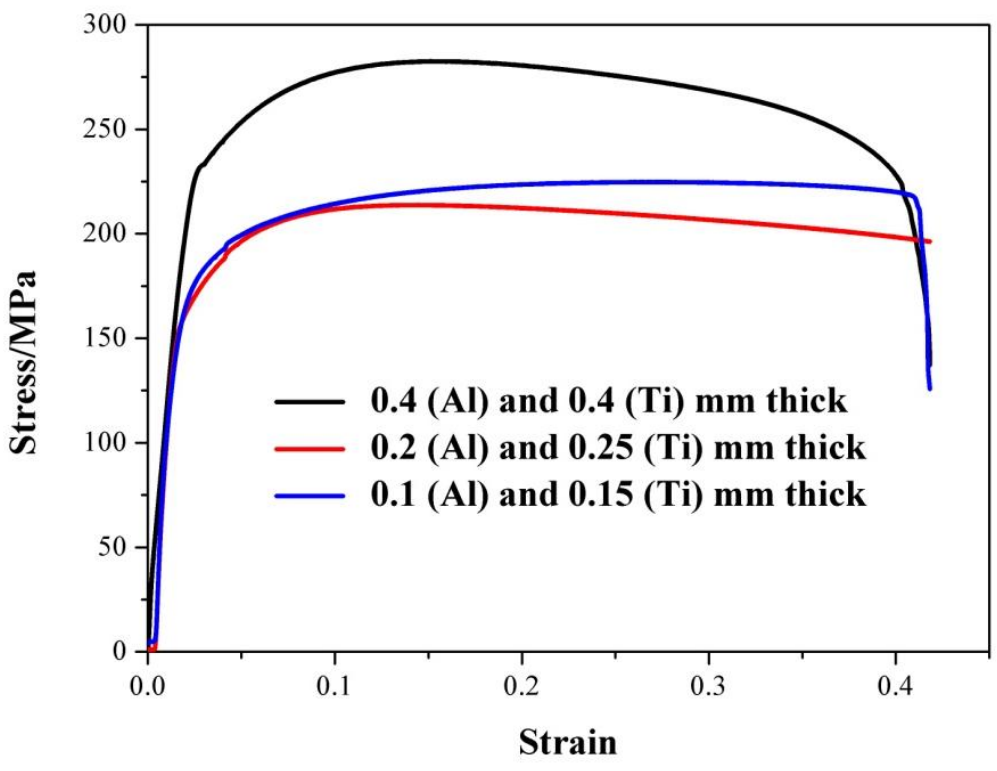

Fig.3 Tensile stress-strain curves of Ti-Al laminate composites 


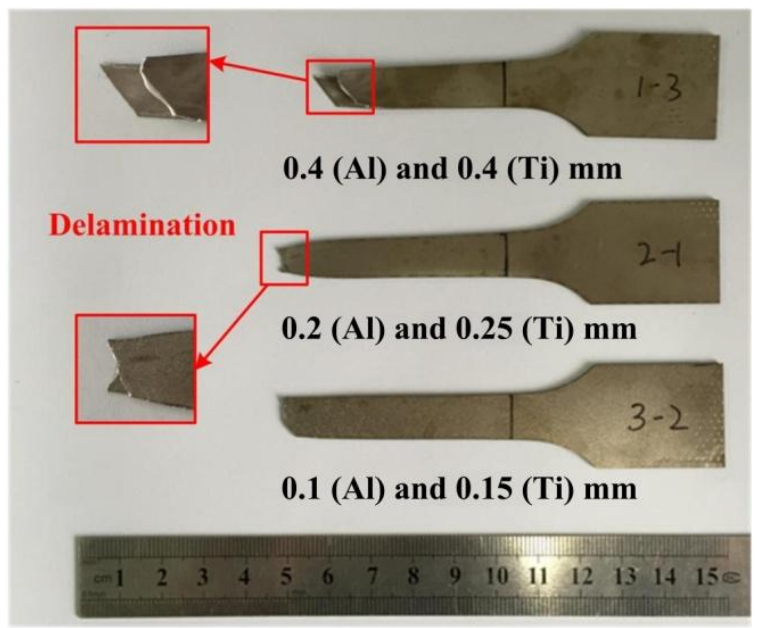

Fig.4 Fracture morphologies of Ti-Al laminate composites 


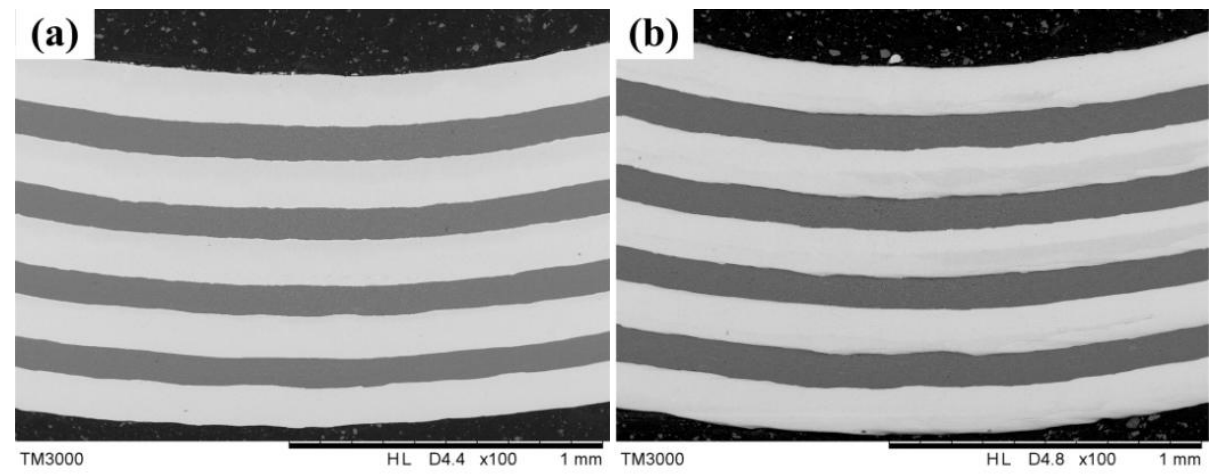

Fig.5 The morphology of the Ti-Al layers at bend angles of (a) $100^{\circ}$ and (b) $110^{\circ}$ 
(a)

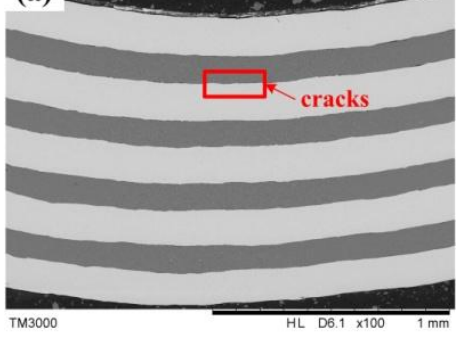

(b)

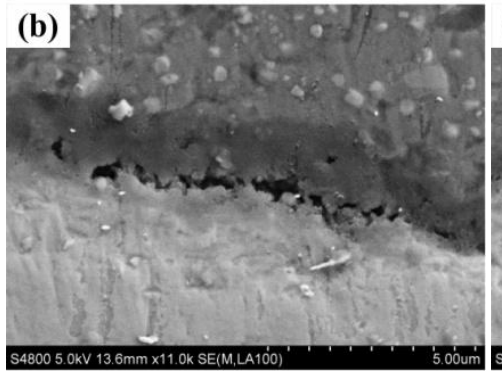

(c)

Fig.6 The morphology of the Ti-Al layers after bending deformation of $120^{\circ}$ : (a) $100 \times$; (b)

$11000 \times$; (c) $12000 \times$ 


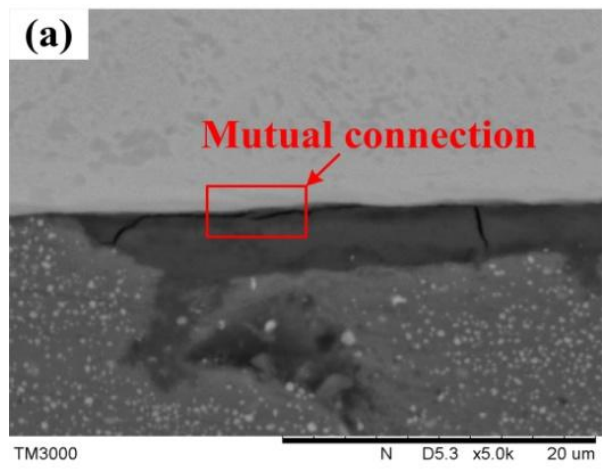

(b)

(c)

(d)



Fig.7 The morphology of the Ti-Al layers after bending deformation: (a) $130^{\circ}$; (b) $140^{\circ}$; (c)

$150^{\circ}$; (d) $160^{\circ}$ 


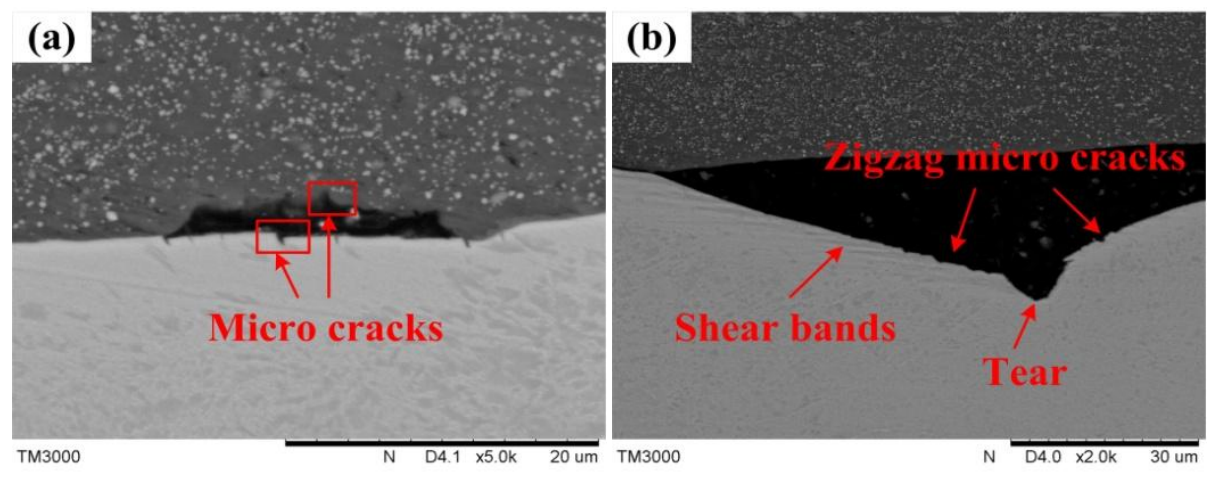

Fig.8 The morphology of the Ti-Al layers after bending deformation: (a) $170^{\circ}$; (b) $180^{\circ}$ 

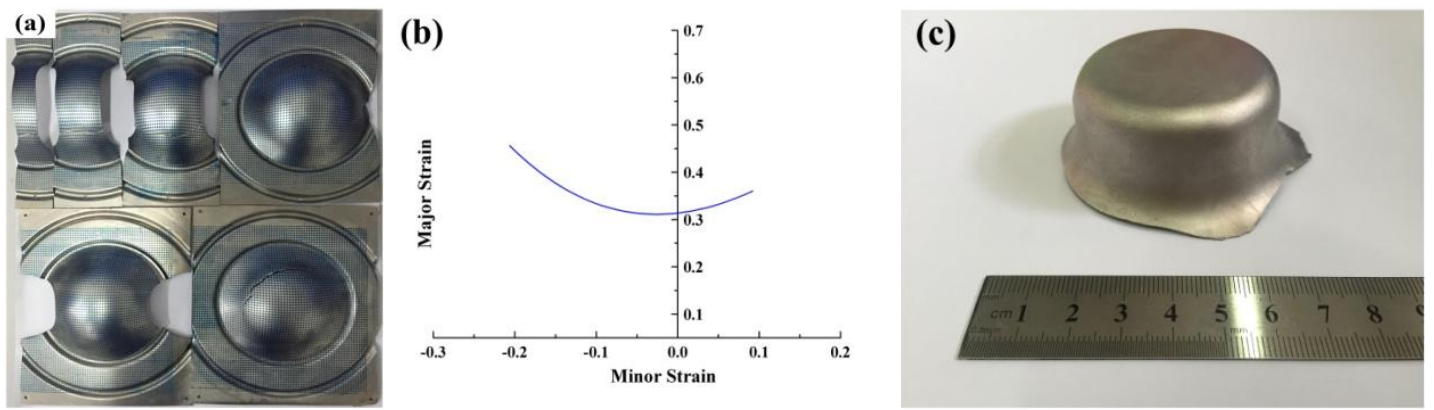

Fig.9 The forming properties of Ti-Al laminate composites: (a) forming limit sheets; (b) forming limit curve; (c) Ti-Al laminated parts 


\section{$0.4 \mathrm{~mm} \mathrm{Ti} 0.4 \mathrm{~mm} \mathrm{Al}$}

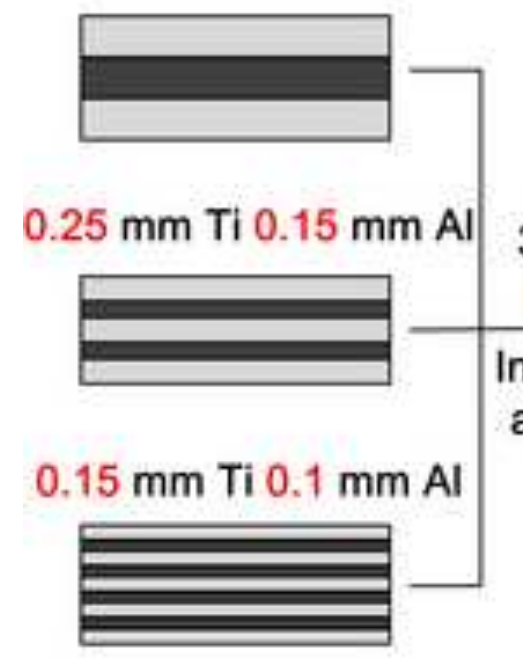

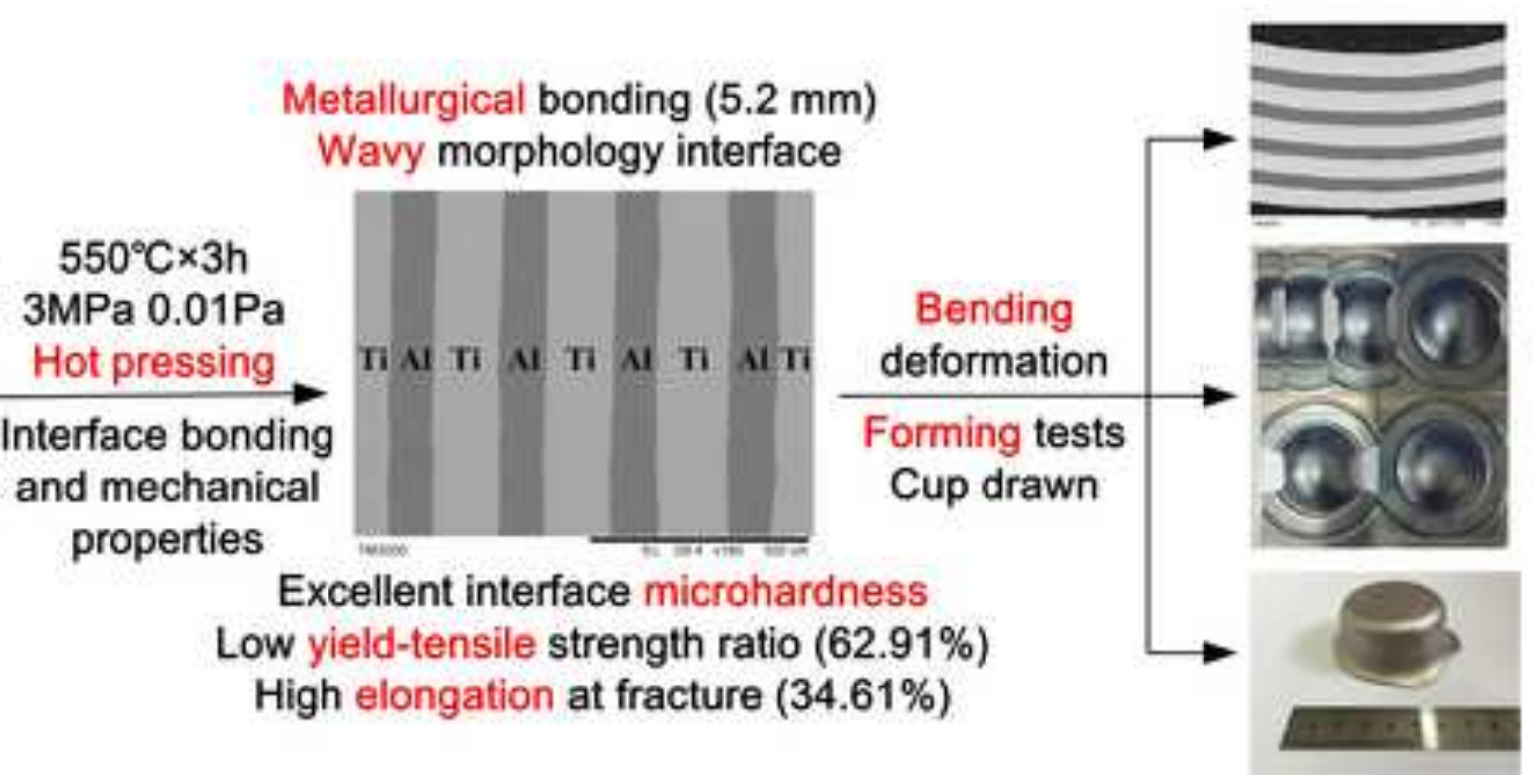

Metallurgical bonding $(5.2 \mathrm{~mm})$ Wavy morphology interface

Excellent interface microhardness ow yield-tensile strength ratio $(62.91 \%)$

High elongation at fracture $(34.61 \%)$

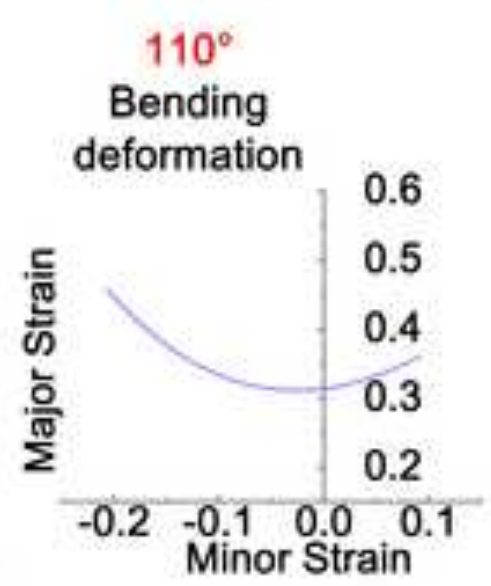

Diameter: $54 \mathrm{~mm}$ Height: $28 \mathrm{~mm}$ 